determinants of health it is different. It may be that the most effective way of reducing coronary heart disease rates 60

\title{
Tackling health inequalities since the Acheson Inquiry
}

\section{G Marmot}

\section{Policies are in place that could make a difference}

ty has been said that there are two types of people in the world: those that think there are two types of people and those who do not. If I were not disbarred by the contradiction, I would belong to the second group. This applies to my view of health inequalities-both to the problem and its solutions. Health inequalities are not confined to differences in health between rich and poor; health follows a social gradient: the higher the position in the social hierarchy, the lower the risk of ill health. Similarly, the policy responses to health inequalities are likely to be graded-shades of grey rather than black and white.

In Britain, we have recognised the problem of health inequalities for a long time. ${ }^{1}$ That is not news. The news would be if a government took seriously reduction of health inequality. Governments take health care seriously. The newspapers and politicians are full of stories about how many nurses or surgeons there are, how much is being spent on health care, how long is the waiting list, how long the wait for surgery. The magnitude of health inequalities is not the currency of daily debate. How, then, could we tell if a government took seriously reduction of health inequalities? They might declare publicly that health inequalities are a problem to be solved; perhaps set in motion a process to garner expert advice to tell them what to do; it might help to set targets for reduction of health inequalities, as an aspiration; policies need to be put in place; and a system set up to determine if any of the policies are having effect.

Based on this list, one could almost conclude that the British government has taken seriously reduction of health inequalities. It is not that they belong to the group of governments that care as distinct from those that don't, but on a scale, it would appear they are at the concerned end. It is worth examining the record.

On election in 1997, the new Labour government announced that they were going to give health inequalities centre place. This was a reversal of the previous medical care. government's policy of ignoring health inequalities; the most egregious evidence of which was the rejection of the Black report on health inequalities. ${ }^{2}$ The way the new government signalled its intent was to set up an Independent Inquiry into Inequalities in Health under the chairmanship of a former chief medical officer, Sir Donald Acheson.* The Acheson group, as had the Black report nearly two decades earlier, took the view that the causes of health inequalities were socioeconomic, were rooted in society, and not primarily the result of unequal access to health care. Acheson's recommendations were, therefore, directed across the whole of government. ${ }^{3}$ Only 3 of the 39 recommendations were to do with

What would the government do with our recommendations? The initial signs were not promising. They welcomed our report. There was no news in that. By comparison, the government of Margaret Thatcher buried the Black report, to the fury of the scientific community and consequent wide publicity. As a member of the Acheson group, I was concerned initially that welcoming our report could be a recipe for doing little-killed with blandness. In fact, they did more than a tepid welcome, considerably more. The government issued a white paper on health strategy, Saving Lives, our Healthier Nation, ${ }^{4}$ in which the two overarching health goals were to improve health and reduce inequalities.

A big question was whether to set numerical targets for reduction of health inequalities. On the one hand, it is difficult to set a target if one cannot calculate the effect of actions. If population concentrations of plasma cholesterol were reduced by $10 \%$ one could make a reasonably precise estimate of the reduction of coronary heart disease that would follow. With social

*The Scientific Advisory Group of the inquiry consisted of Donald Acheson, David Barker, Jacky Chambers, Hilary Graham Michae Marmot, Margaret Whitehead and Scientific secretary Catherine Law, and Administrative Secretary, Ray Earwicker. years from now is to invest in early child development today. But no one could, at the present state of knowledge, put a quantitative estimate on that effect. How then is it feasible to set numerical targets? On the other hand, the setting of targets is aspirational. If taken seriously, it concentrates attention on what can be done.

In the event, the government set two targets: one for life expectancy between regions and one for infant mortality. If it is accepted that health inequalities are graded, how should the social gradient be reflected in the setting of targets? A target for a measure such as the relative index of inequality ${ }^{5}$ would have little public recognition. One way of doing this is the way the government chose: to reduce by $10 \%$ the gap in infant mortality between manual groups and the population as a whole. This is deceptively challenging. It means moving about half the population towards the average, which will change as the bottom half improves. It may not be an explicit recognition of the gradient, but it is a clear statement that health inequalities are not confined to poor health for those at the bottom.

In terms of our scorecard to see if government were serious about health inequalities, so far so good: national recognition, assembly of expert opinion, and setting of targets. Did anything real get put in place with respect to actual policies? To answer that question we set up a post-Acheson inquiry with the aim of determining what policies the government had put in place that were likely to have a favourable effect on reducing health inequalities. ${ }^{6}$ It would, of course, be of great interest to know if the Acheson Inquiry was the direct cause of the policies, but such ascertainment is difficult. A government that set up Acheson is likely to be one that cares about inequality and fairness in society. If such care leads to policies, they are likely to have an impact on health inequalities.

It is important to distinguish at least three aspects of policies. Is there a policy to improve things, is that policy actually making a difference on the ground, and is it having an impact on health inequalities. For example, there may be a recognition that inadequate and expensive public transport contributes to the disadvantage of non-car owners and there may then be a high sounding policy to improve access to public transport. If, as seems the case, there is no evidence of improvement in access to public transport, it cannot have an impact on health inequalities. 
In general, asking to see an impact on health inequalities in the short term may be a little unrealistic. One does, however, want to see evidence of policies being put into action that might make a difference. Our review suggested that actions were in place. Our report pointed to a number of policy areas. Firstly, attention to the early years of life; examples being the Sure Start programme aimed at child development for $0-3$ year olds in deprived areas; and a commitment to reduction of child poverty. Secondly, area based initiatives with the creation of health action zones. Thirdly, income redistribution; changes in tax credits were aimed at making work more attractive financially. This complemented New Deal schemes aimed at getting people off welfare and into work. Fourthly, substantial reforms in the National Health Service; whether these will lead to more equal access remains to be seen. Fifthly, there is a general culture of targets and monitoring of performance. The health inequality targets are part of that. The Department of Health has a so called Public Service Agreement to deliver on these health inequality targets. Sixthly, mechanisms have been put in place that make concerted action more likely.
In the last category, there has been a "cross cutting" spending review on health inequalities. As long as health inequalities were the "property" of the Department of Health it would be difficult to ensure that appropriate action was taken across other government departments. This cross cutting spending review was led by the Treasury and involved departments, units, and agencies across the whole of government. Representatives of departments, who had never thought that their actions might influence health, or health inequalities, were asked to review their policies with a view to shaping them to reduce health inequalities. Reduction in crime, for example, was now seen as a policy that could have a favourable impact on health inequalities.

If one were a binary classifier, commentators in Britain could be divided into two types; those who think that governments are the agent of the devil, and those who think the world is more complicated. (Note the absence of commentators who think governments are angels.) Our report, Tackling health inequalities, showed that there is much activity that is likely to have a favourable impact on health inequalities. It has to be set alongside an overall increase in income inequality that changes to the tax regime have not entirely countered. Will these government actions lead to a reduction in inequalities? The monitoring of what happens over the rest of this decade and beyond will be of intense interest.

$J$ Epidemiol Community Health

2004;58:262-263.

doi: 10.1136/jech.2003.010264

Correspondence to: M G Marmot, International Centre for Health and Society, Department of Epidemiology and Public Health, University College London, 1-19 Torrington Place, London WCIE 6BT, UK; m.marmot@

public-health.ucl.ac.uk

\section{REFERENCES}

1 Farr W. Letter to the registrar general. In: First annual report of the registrar general. London: HMSO, 1839

2 Department of Health and Social Security. Inequalities in health: report of a Research Working Group Chaired by Sir Douglas Black. London: DHSS, 1980.

3 Acheson D. Inequalities in health: report of an independent inquiry. London: HMSO, 1998.

4 Department of Health. Saving lives: our healthier nation. London: Stationery Office, 1999.

5 Kunst AE, Mackenbach JP. The size of mortality differences associated with educational level in nine industrialized countries. Am J Public Health 1994;84:932-7.

6 Exworthy M, Stuart M, Blane D, et al. Tackling health inequalities since the Acheson Inquiry. Bristol: The Policy Press, 2003.

\section{When I'm 64 ... will you still need me? Epidemiology in country practice: W H Pickles, 1939*}

\section{J A Reid}

A seminal book that has been read and assessed during past decades by many public health students and practitioners is now 64 years old. Can it still offer insight, inspiration, and renewal for public health as it approaches 65 , or should it be pensioned off?

This reader friendly narrative covers many interesting and educational themes, public health scientific (communicable diseases) issues of the day,

*W H Pickles. Epidemiology in country prac tice. Torquay, Devon: The Devonshire Press 1939 (reprinted by the Royal College of General Practitioners, London, in 1984, 128 pages, £16.50, ISBN' 0-85084-097-X) and helps illustrate the work of a GP and also rural life in Wensleydale through the 1930s. However, it is important to dwell on the overall feel about Pickles that comes from this work.

Pickles demonstrates key elements of a public health leader; good (written and listening) communication skills, being ahead of his time, exploring challenging issues for science and society, systematic interest in health and disease and its determinants, a good humanitarian empathy for real people and their problems, and a seeming aptitude for partnership work to support the grand, more strategic project of his local epidemiological profiling.

Lessons from Pickles' work still have resonance in contemporary and future scenarios for public health and primary care. Geographical well demarcated village communities facilitated the clear identification and sense of ownership by Pickles with the local population. Also living within them as neighbours and in social activities was part of the continuity and understanding built up over years of practice. It is still feasible for rural GPs to do this, but also for urban GPs with their own registered population can look at the health of those people with their own partners, as part of neighbourhood or locality public health, or within the primary care trust's overall public health remit, or indeed within the wider local public health network.

Pickles acted as a narrator and recorder of the health experience of the local population. This was legitimate in that there was no competition, rivalry, and fear from other practices, as he and his partner covered a defined population of their own. His legitimacy also stemmed from his position as part time medical officer of health. His scientific and organisational credibility was probably enhanced by links to 
public health officials and academics. He was able to recognise potential for partnership and developing public health capacity; demonstrated in looking to his wife and daughter for support in his recording and in harnessing interest of school head teachers. The latter in recognition of his interest in schools as population groups and as opportunities for understanding spread of infection.

His systematic recording and presentation of charts of infection was noteworthy, as was his attention to details of history of travel, occupation, social interaction, and clinical features including onset dates.

His amusing insights into human behaviour have resonance today. The grim statistics of re-emergence of sexually transmitted diseases might have more striking impact if they were written about in a more rounded fashion, giving qualitative and personal experience more prominence alongside the statistics. This was partly evident during the original documentation of HIV and AIDS transmission and risk behaviour.

The clinical typification he used has more recently been witnessed as fundamental underpinning of understanding and responses to new diseases like vCJD and SARS. His work on mumps echoes down the years, given the recurrence today among unprotected older teenage groups in secondary schools and colleges. His demonstration of outbreaks of Shigella sonnei and hepatitis A (epidemic catarrhal jaundice) evoked memories of some of the school based outbreaks I investigated in the 1980s.

What, in consequence of the above, about the future relevance? I would propose several lines of inquiry to take Pickles' work towards its centenary in 2039.

(1) GPs and other primary care clinicians need support to enable them to undertake public health and epidemiological roles within the modern primary care setting. Although medical leadership is important, relevant work with school nurses and locality nurses are great opportunities for showing local population needs. The GP role could be facilitated by, for instance, the following:

(2) Review of existing strengths (for example, sentinel surveillance and leading edge projects) and weaknesses (problems with data capture, quality, and sharing).

(3) Taking advantage of electronic patient records in primary care to produce higher quality patient datasets amenable to systematic analysis. This may build up from recent experience in setting up mental health, diabetes, and CHD other chronic disease registers. Much in incorporate epidemiology is still missed.

(4) Recognition of GP involvement in leading some work on relevant clinical health problems within the primary care trust LIS. The new GP contract offers scope for GP specialisation and attendant remuneration. Such work could also count for GP personal development and revalidation, including gaining credits for additional qualifications, CPD, audit or research or teaching.
(5) The position for several interested GPs in each as "health recorders" could be linked to primary care trust public health departments and supported through analytical support, training, and publishing facilities. Perhaps such recorders should be asked to produce a five yearly account on the population.

(6) The academic credibility of Pickles' legacy could be strengthened by establishment of repositories of output from recorders (linked to public health observatories), prize giving, awards, and celebration of good practice, by publication of innovation or new evidence.

Pickles' wider work with schools and communities can also be taken forward. Partnerships with local education authorities should take the opportunity to harness local interest in ICT (information and communication technology) to produce regular account of pupil/ student health from school absence registers, surveillance, and assessments of health. Community, voluntary, and statutory agencies can collaborate to produce health profiles that are wanted and needed.

A putative 'Pickles collaborative' has as much resonance as those of "Cochrane" and "Campbell" for future public health.

$J$ Epidemiol Community Health 2004;58:263-264.

doi: 10.1136/jech.2003.015230

Correspondence to: J A Reid, Cheshire and Merseyside Health Protection Agency, Suite E, Moorgate Point, Moorgate Road, Knowsley Industrial Park, Kirkby, Merseyside L33 7XW, UK; John.Reid@centralliverpoolpct. nhs.uk

\section{APHORISM OF THE MONTH}

\section{"Sometimes it is necessary to forget your principles and do the right thing" (Lowell Levin)}

W

hether it be on questions of induced abortion, drugs, alcohol, tobacco, or conjugal visits in prison, the satisfaction of maintaining a pure, ethical, and moral position has to be considered against the reality of dead and maimed women and orphaned children from backstreet abortions, of the homicide and community mayhem caused by drug barons dominating the commercial sale of mind altering substances, or people coming out of prison more damaged than when they went in, and the impact of family breakdown on prisoners' families. Public health must be pragmatic if it is to maintain its humanitarian goals. 